\title{
The Aggregation Problem: Implications for Ecological and Biophysical Economics
}

\author{
Blair Fix*
}

November 7, 2018

\begin{abstract}
This paper discusses the dimension problem in economic aggregation, as it relates to ecological and biophysical economics. The dimension problem consists of a simple dilemma: when we aggregate, the observer must choose the dimension of analysis. The dilemma is that this choice affects the resulting measurement. This means that aggregate measurements are dependent on one's goals, and on underlying theory. I explore the consequences of this predicament for ecological and biophysical economics. I discuss the many problems of using 'real' monetary value as the dimension of analysis. And I highlight how the dimension problem undermines the practice of seeking 'optimal' policy. Although there are no solutions, I discuss ways that ecological and biophysical economists can deal with the dimension problem.
\end{abstract}

Keywords: aggregation; dimensions; real GDP; sustainability indexes; optimal policy

*Author contact: blairfix@gmail.com 


\section{Introduction}

Aggregation is the practice of combining the multidimensional into a single dimension. It is used in all aspects of science. Aggregation occurs when a physicist sums the mass of many particles, or when an ecologist sums the energy consumption of an ecosystem. The use of aggregation is so commonplace that its epistemology is often given little thought. This is particularly true in economics - a field that tends to hide epistemological questions under a fog of mathematics (Mirowski, 1991; Keen, 2001). Aggregation is often portrayed as a purely objective process. After all what could be more objective than the act of adding things up?

This paper highlights some basic problems with aggregation in economics. As I see it, aggregation involves two types of decisions:

1. Choosing a system boundary;

2. Choosing a measurement dimension.

When we choose a system boundary, we decide what to include in our measurement, and what to exclude. When we chose a measurement dimension, we decide how to make the incommensurable commensurable. The problem is that both boundary and dimensional choices are subjective - they depend on our goals. Yet these decisions affect the resulting aggregation. Giampietro, Allen and Mayumi (2006) call this the "epistemological predicament associated with purposive quantitative analysis" - "the observer always affects what is observed when defining the descriptive domain".

This paper explores the aggregation predicament, with a specific focus on measurement dimensions. I discuss how dimensional problems affect economic aggregation, and explore the implications for ecological and biophysical economics.

\subsection{Moving Beyond the 'Boundary Critique'}

Critics of economic aggregation usually focus on boundary decisions. This is understandable. The national accounts are based on dubious boundary choices. For instance, they exclude unpaid domestic work (Messac, 2018; Waring, 1999). They also exclude environmental degradation, social 'bads', resource depletion, and ecosystem services (Daly and Cobb, 1994; Daly and Farley, 2011; Dixon and Hamilton, 1996; Costanza and Daly, 1992; Kubiszewski et al, 2013).

I agree that the national accounts use questionable boundaries. I also agree that choosing 'better' boundaries seems like a good idea. However, I am con- 
cerned that the 'boundary critique' distracts us from a more fundamental problem. Economists have based their accounting system on the dimension of monetary value. Yet this dimension is unstable. Prices change over time in divergent ways. This changing meter stick wreaks havoc with objective measurement. Should we reform a system based on such an unreliable dimension? I argue we should not. Instead, we need to ask some more basic questions. What are we trying to sustain? What dimension is appropriate? There are no simple answers. But as long as we focus only on boundaries, we will not ask these important questions.

\subsection{Goals}

This paper has three goals. The first goal is to show how dimensional choices affect aggregation (Section 2). When we choose dimensions, we choose how to weight different attributes against one another. The problem is that this choice affects the resulting aggregation. The usefulness of an aggregation thus depends on agreement about the appropriate dimension. If our goals are contested and the relevant dimensions are ambiguous, aggregation should be avoided.

My second goal is to show what goes wrong when we choose monetary value as the aggregation dimension (Section 3). The national accounts use monetary value to aggregate economic output (among other things). I discuss how dimensional problems undermine this approach. The problem is that prices - our unit of analysis - are unstable over time. This instability wreaks havoc with objective measurement. When we attempt to 'correct' for inflation, we must make many subjective decisions. The result is a measure that is riddled with uncertainty. I discuss how this affects attempts at national accounts boundary reforms. I also discuss the implications for economic growth accounting.

My third goal is to highlight how the dimension problem affects economic decision-making (Section 4). Neoclassical economists often claim to identify policies that are optimal (i.e. best for everybody). This approach has significantly influenced sustainability policy. Yet it has a simple problem. Optimization requires aggregation. Thus, the search for 'optimal' policy inherits all the dimensional pitfalls of aggregation itself. To deal with these problems, I propose a checklist to determine if optimization is appropriate. If the checklist is not met, then the use of optimization is likely pernicious. It gives ethical and moral preferences the appearance of scientific rigor.

I conclude with thoughts about how to address the aggregation dimension problem (Section 5). Although there are no 'solutions', there are ways to cope 
with the problem. For too long, economic aggregation problems have simply been ignored. If economics is to be reintegrated with the natural sciences (Hall et al, 2001), these issues must be addressed.

\section{The Dimension Problem}

Aggregation requires making the incommensurable commensurable. We begin with incommensurable items - 'apples' and 'oranges' — and then use a common dimension to make them commensurable. The dimension converts qualities into quantities that can then be universally compared.

Throughout this paper I will speak of dimension choice, a concept that is likely foreign to many natural scientists. In the context of basic science, dimensions are not usually thought of as a 'choice' - they are usually taken as a given. For instance, if we want to measure inertia, it is taken as a given that we should use the dimension of mass. This stems from the universal acceptance of Newton's laws, which state that resistance to acceleration (inertia) is proportional to mass. But it has not always been obvious that mass is the only relevant dimension for inertia. On Earth a feather falls more slowly than a brick. Does this mean that inertia is related to the dimension of surface area? That we can exclude this possibility is an important scientific achievement.

In economics, things are quite different. For instance, there is no well-tested theory that singles out the correct dimension for economic output. In economics, aggregation dimensions are a subjective choice. The dimension problem stems from this choice. Simply put, the subjective choice of dimension affects the aggregation.

\subsection{When There is No Dimension Problem}

Let's begin with instances when there is no dimension problem. This happens when we aggregate items that are identical and unchanging. In this case, we are aggregating items that are already commensurable. Thus dimensional choices do not affect the aggregation.

This is illustrated in Figure 1. Here we imagine aggregating a stock of identical apples. Clearly the apple stock in Scenario A is half that of Scenario B. This is true no matter what dimensions we use to aggregate apples (mass, volume, energy, etc.). Since all apples are identical, they all share the same attributes. Thus the choice of attribute does not affect the stock-size ratio between the two 
scenarios. There is no dimension problem because aggregation reduces to arithmetic.

$$
\begin{aligned}
& \text { Scenario A: } \\
& \text { Scenario B: }
\end{aligned}
$$

\section{Figure 1: Unambiguous Aggregation}

This type of aggregation is something we rarely do in the real world. Yet it is a common assumption in economic theory. For instance, Robert Solow (1956) begins his famous treatise on economic growth theory by assuming that "There is only one commodity, output as a whole". His reason for doing so is telling. It is so he can "speak unambiguously of the community's real income" (ibid). What does he mean by this? Solow is essentially assuming away the dimension problem. In a one-commodity economy, dimensional choices do not affect the measured growth of economic output. Thus changes in output are completely unambiguous, as are changes in real income.

Solow is not alone in making this assumption. The single-commodity economy is a foundational assumption in neoclassical theory. For instance, Colacchio (2018) observes that "the only case consistent with the [neoclassical] marginal productivity theory is that of a 'one-commodity' economy". Neoclassical economic theory assumes a world in which there is no ambiguity in aggregation. That this assumption is obviously violated in the real world is a searing indictment of the theory.

\subsection{Illustrating the Dimension Problem}

I now move on to the more realistic scenario of aggregating items that are not identical. In this situation, the choice of dimension is not neutral.

The best way to understand the dimension problem is through a twocommodity example. Suppose we are shopkeepers who have a stock of apples and bread slices. Like many shopkeepers, we are not satisfied to state that we have $x$ apples and $y$ slices of bread. Instead, we want to know the size of our total inventory. How do we go about calculating this quantity?

Let's set aside the fact that most shopkeepers care about the monetary value of their stock. (I will deal with monetary value later). Instead, let's assume that we want a physical measure of the size of our stock. This is simple enough to do - we just need to choose a dimension of analysis. Let's choose between 
dimensions of mass, volume, and energy. Table 1 shows realistic values for the average mass, volume and energy content of apples and bread slices. We simply choose one of these dimensions, and use it to aggregate our total stock.

Table 1: Measuring apples and bread slices using different dimensions

\begin{tabular}{lccc}
\hline & Mass $(\mathrm{g})$ & Volume $\left(\mathrm{cm}^{3}\right)$ & Energy (cal) \\
\hline Apple & 75 & 104 & 39 \\
Bread Slice & 30 & 52 & 79 \\
\hline
\end{tabular}

But there is a problem. The choice of dimension is subjective - it depends on our goals. Yet this choice plays a crucial role in determining the measurement results. To understand this dilemma, it is helpful to reflect on what choosing a dimension does. The dimension determines the relative weight assigned to each element. In our example, the dimension determines how we weight apples relative to bread slices. The problem is that different dimensions lead to different weightings. The dimensions of mass, volume, and energy lead to the following weightings between apples and bread slices:

$$
\begin{aligned}
\text { Mass: } & 1 \text { apple }=2.5 \text { bread slices } \\
\text { Volume: } & 1 \text { apple }=2.0 \text { bread slices } \\
\text { Energy: } & 1 \text { apple }=0.5 \text { bread slices }
\end{aligned}
$$

These different weightings can lead to divergent measures for the aggregate stock of apples and bread slices. We can illustrate this problem by constructing an indexed time series of the size of our stock. Over a period of 30 hours, suppose the individual stock of apples and bread slices changed as shown in Figure 2A. Assuming that apples and bread slices are uniform, we can state that the stock of bread slices increased by $164 \%$, while the stock of apples decreased by $70 \%$. There is no ambiguity here. We would get the same result no matter what dimension of analysis we chose for each series.

However, this is not true when we move to an aggregate analysis. Figure 2B shows the indexed growth of the aggregate apple-bread stock. Three time series are shown - one for each dimension of analysis. Note the significant discrepancy between the three series. When measured in terms of caloric energy, the size of our apple-bread stock increases by $86 \%$. Yet when measured in terms of mass, the same stock appears to decrease in size by $3 \%$. What is going on here? 

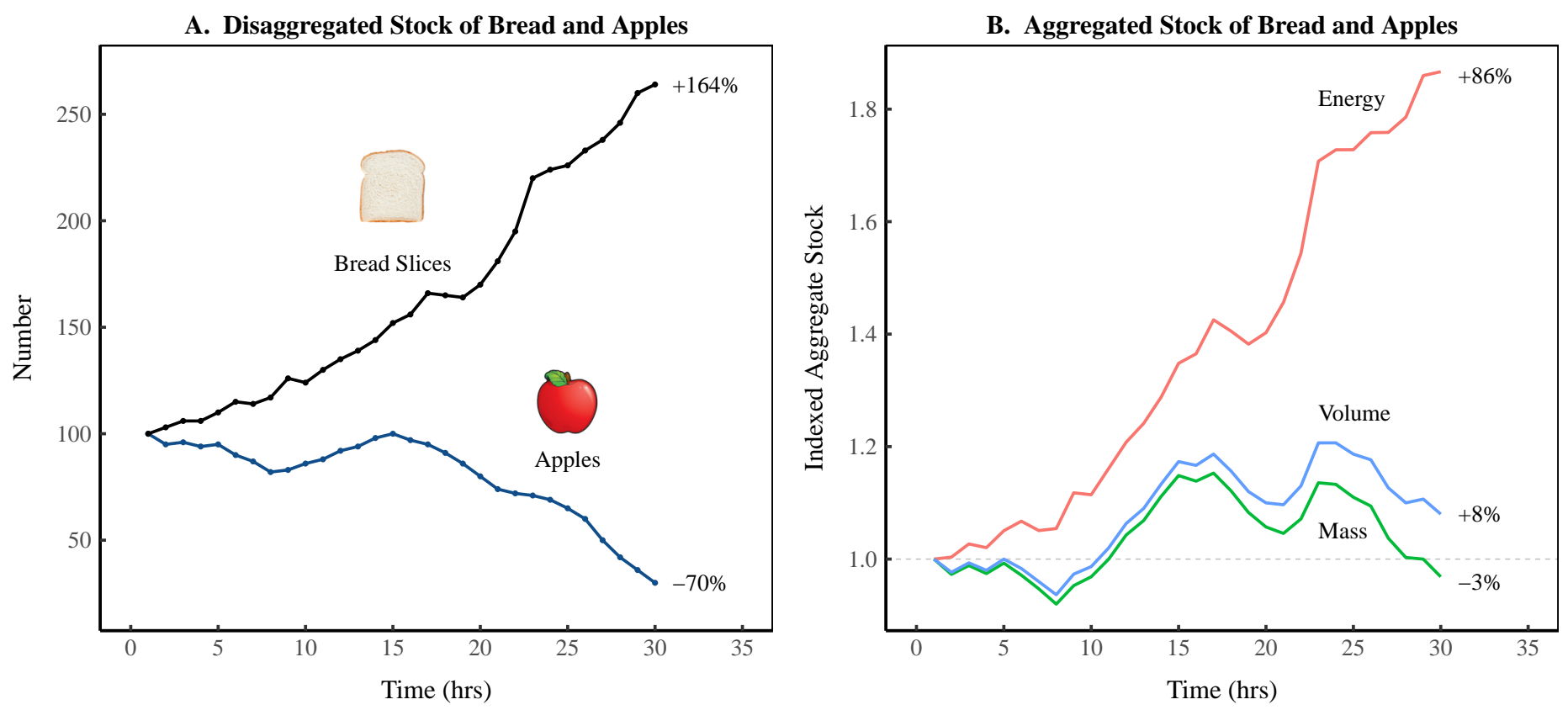

Figure 2: Aggregating a Stock of Apples and Bread slices

This figure shows how the choice of dimension of analysis affects aggregate measures of quantity. We imagine that a shopkeeper has a stock of apples and bread slices. Panel A shows how the number of apples and bread slices changes over a period of 30 hours. Panel B shows three different indexed aggregate measures of the same stock, calculated using dimensions of energy, volume, and mass (with values from Table 1). Different dimensions lead to a different weighting between apples and bread slices, which causes divergent measures for the growth of the aggregate stock. This figure is inspired by Fig. 8.1 in Nitzan and Bichler (2009).

This large discrepancy is caused by our dimensions. When we change dimensions, we change the relative weighting between apples and bread slices. This affects how much we weight the increase in the number of bread slices against the decrease in the number of apples. The result is a divergence in the indexed growth of our stock.

It might seem reasonable to ask - which index is the 'correct' measure of aggregate quantity? However this question is ill posed. All three measures are correct in a mathematical sense. Instead, we should ask - which measurement is appropriate given our goals? It is here that subjectivity enters the equation. Suppose we want to use our stock to feed a starving population. In this context, caloric energy content seems the most appropriate choice of dimension. But if we wanted to calculate shipping costs, then mass is likely the best dimen- 
sion. The choice of dimension depends on our goals. Yet it affects the aggregate measurement. This is the crux of the dimension problem.

This dilemma means that when the appropriate dimension is unclear or contested, aggregation may be unwise. For instance, suppose we want to aggregate fresh water and bituminous coal to create an index of 'natural capital'. It is unclear what dimension we should use. Fresh water and bituminous coal have completely different uses. If we value objectivity, it is likely better to treat water and coal as incommensurable. In other words, we should avoid aggregation.

To summarize, aggregation requires subjective choices about the dimension of analysis. These choices then affect the resulting measurement. Once it is pointed out, the dimension problem is simple to understand. It borders on trivial. Yet it has far-reaching consequences for economics. By the end of this paper, the reader should see a repeating story. Aggregation requires subjective decisions. Unsurprisingly, economists make subjective decisions in order to aggregate. But here is the unsettling part. They do not acknowledge that these decisions are subjective. Moreover, they do not explore the consequences of making different decisions. This behavior is an anathema to good science. It needs to be fixed if we wish to construct a legitimate "science of sustainability" (Dodds, 1997).

\section{Monetary Value: The Changing Meter Stick}

I move now to a dimension problem that is unique to economics. A defining feature of economics is its use of monetary value as a dimension of analysis. I will first discuss when this is unproblematic. If our interest is in prices themselves, then monetary value is a valid dimension of analysis. However, economists often use prices to measure 'real' quantities of production. When used this way, we run into a sea of epistemological problems. The result is irreducible measurement uncertainty.

\subsection{Prices for their Own Sake? Or Prices for 'Real' Quantities?}

There are two ways to think about money and prices. The first is to think like a capitalist. The second is to think like an economist.

Capitalists are interested in prices for their own sake. A capitalist does not generally care 'what' or 'how much' he owns (in any physical sense). Instead, he cares about the monetary value of what he owns. And this is only relevant in comparison to the value of other things. Nitzan and Bichler (2009) observe that 
capitalists are interested in differential comparison - comparing the monetary value of one thing to another (at a given point in time). If we aggregate monetary value for differential comparison, there are no epistemological problems (although we may raise ethical objections).

In contrast, economists are generally not interested in prices for their own sake. ${ }^{1}$ Instead, they are interested in the 'real' sphere of production. Economists want to know 'what' and 'how much' is produced. Prices are merely the window into this 'real sphere' - a facade that needs to be removed. Economists suppose that aggregate market value $(Y)$ can be divided into two components - prices $(P)$ and some 'real' quantity of production $Q$ :

$$
Y=P \cdot Q
$$

The quantity of production $Q$ is then given by $Y / P$. This method is how 'real' GDP is calculated. We take nominal GDP and 'adjust' for inflation using a price index. The result is 'real' GDP - the 'real' quantity of production.

This type of 'real' measurement is a foundational goal of the national accounts. Taken at face value it appears to be unproblematic. But when we dig beneath the surface, we find that 'adjusting' for inflation requires a host of subjective decisions. The problem is that prices are an unstable unit - a changing meter stick that wreaks havoc with objective measurement.

\subsection{The Purpose of a Unit}

What goes wrong when we aggregate using 'real' monetary value? To understand the problem, we need to understand the measurement role of units. A unit's purpose is to be uniform. Thus, when we use a meter stick, the actual length of the stick is not important. What matters is that every meter stick is as close to the same length as possible. For this reason, scientists devote great effort to precisely defining units. For instance, the meter is now defined as the length of the path traveled by light in vacuum during a time interval of $1 / 299,792,458$ of a second (Petley, 1983).

A clearly defined unit makes precise measurement possible. Conversely, a poorly defined unit makes precise measurement impossible. Consider the 'foot' as a unit of measure. Although it is now precisely defined, the 'foot' originates in the practice of using literal human feet to measure length (Dilke and Dilke,

\footnotetext{
${ }^{1}$ This position was summarized by John Stuart Mill (1848) when he wrote: "There cannot ... be intrinsically a more insignificant thing, in the economy of society, than money."
} 
1987). Since foot size varies between individuals, we can imagine how this led to uncertainty in measurement. Prices, it turns out, fail the uniformity condition in a spectacular way. This means that they fail as a unit of measure.

\subsection{Divergent Price Change}

The problem is not so much that prices change - it is that prices change in nonuniform ways. I want to emphasize this point, because we often think of inflation as a uniform increase in all prices. If this was true, 'correcting' for inflation would be unproblematic. In reality, price change is not uniform. It varies dramatically between different commodities.

Figures $3 \mathrm{~A}$ and $3 \mathrm{~B}$ illustrate this effect using data from the US consumer price index (CPI). Figure 3A shows price changes for ten selected CPI commodities, while Figure 3B shows price changes for all CPI commodities. The range of price change is astonishing. Since 1935, the price of apples increased by a factor of 50 , the price of electricity increased by a factor of 7 , and the price of TVs actually declined. (TV price decline has mostly to do with quality adjustments, discussed below).

This divergent price change means that our unit is unstable. The effect on aggregation is the same as when we changed dimensions in our apple-bread example (Fig. 2). Divergent price changes cause the relative weighting between commodities to change with time. This means that our measure of aggregate quantity is affected by our choice of price 'base-year'. This problem was identified over a century ago by Francis Edgeworth (1887):

If one great group of commodities varies pretty uniformly in one direction, and another in a different direction (or even in the same direction but in a markedly different degree), then the task of restoring the level of prices can no longer be regarded as a purely objective ... problem. (cited in Vining and Elwertowski (1976))[emphasis added]

To quantify the scale of the problem, we can calculate the relative standard deviation of US price change. (Relative standard deviation is defined as the standard deviation divided by the mean). Between 1935 and 2013, price change for all CPI commodities had a relative standard deviation of about $40 \%$. This $40 \%$ uncertainty makes other poorly defined units look precise in comparison. Consider the unit of the 'man', defined as the length of the man doing the measuring. It is hard to imagine doing accurate science with this length unit. Yet the uncertainty in male height is only about $4 \% .^{2}$ Thus, the unit of the 'man' is about 10 
times more accurate than using US prices as a unit of measure.

\subsection{Price Instability Leads to Real GDP Uncertainty}

The problem with price instability is that it leads to ambiguity when we try to 'adjust' for inflation. This leads to ambiguity in time-series based on 'real' monetary value. Let's use real GDP as an example. The ambiguity in real GDP is not easy to spot. Governments publish only a single official measure of real GDP, and they do not report uncertainty. But if we look under the hood of real GDP calculations, we find significant ambiguity.

Let's review the problem. To calculate real GDP, we pick a base year and hold prices constant. Prices in this year assign a relative weight to each commodity. We then use these weights to aggregate all commodities into a single measure of economic output. The problem is that prices change in non-uniform ways over time. This means that different base years assign a different weighting between commodities. The choice of base year therefore affects the growth of real GDP. Since the choice of base year is subjective, we are left with unavoidable ambiguity in our measure. (This problem is the same as the dimension problem illustrated in Figure 2. When we change base-year prices, the effect is the same as literally changing dimensions).

Sometimes the base-year effect can be enormous. Nigeria recently switched from a 1990 to a 2010 base year, resulting in a doubling of GDP (Blas and Wallis, 2014). A similar doubling of GDP occurred when Ghana changed its base year from 1993 to 2006. Base-year revisions in Botswana, Kenya, Tanzania and Zambia have also led to large changes in GDP (Jerven, 2012, 2014).

In the US, the uncertainty in real GDP growth is sizable. Figure 3C shows how the choice of base year affects the growth of US real GDP per capita. This analysis indicates a 30\% uncertainty in the growth of US GDP per capita over the last 60 years. This estimate is conservative because it does not include the uncertainty involved in quality-change adjustments (discussed below). Interestingly, the official measure of real GDP growth (dashed line) is at the upper end of the uncertainty range. Is this a coincidence? It would be interesting to repeat this analysis for other countries to see if official real GDP measures always lie at the upper end of the base-year uncertainty range. This would indicate systematic bias in government methods.

Of course, measurement uncertainty is an unavoidable part of empirical science. Good science requires being honest and open about measurement un-

\footnotetext{
${ }^{2}$ The relative standard deviation of adult males is roughly $4 \%$ (Smith et al, 2000).
} 


\section{A. Ten Selected US CPI Price Indices}

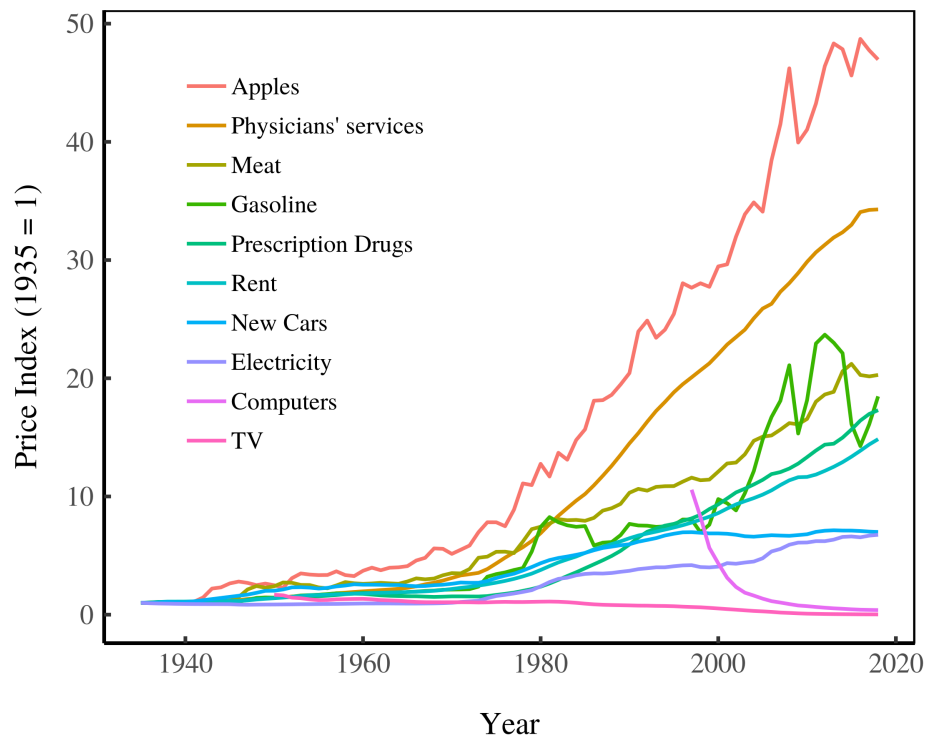

C. Divergent Measures of US Real GDP per Capita

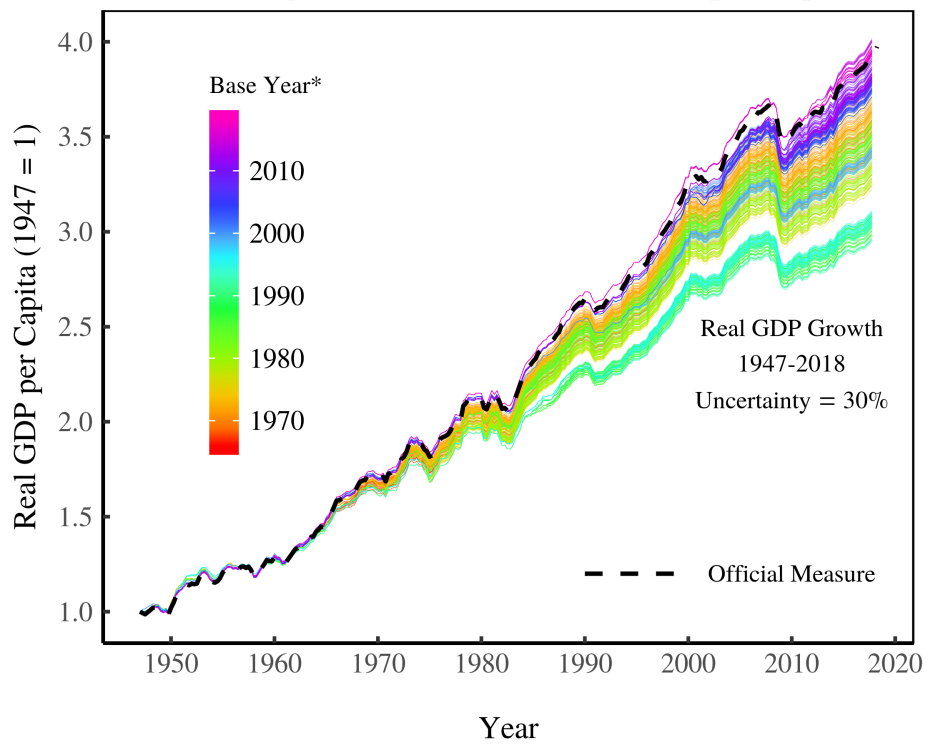

B. All US CPI Price Indices

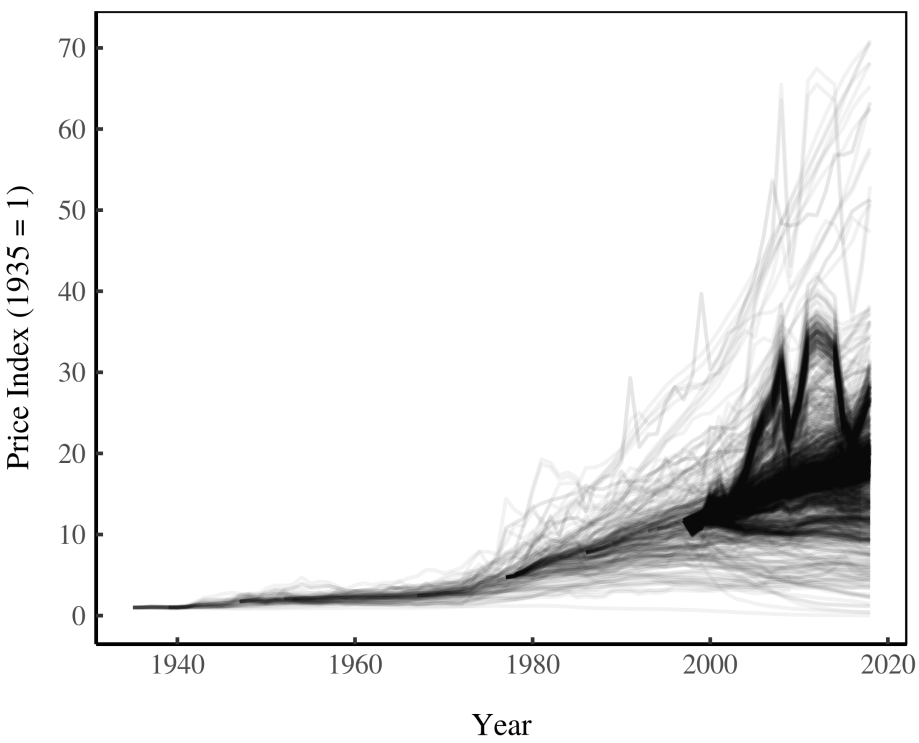

Figure 3: Divergent Price Change and Divergent Measure of Real GDP

This figure shows how divergent changes in price affect the measurement of US real GDP. Panel A shows historical price changes in ten selected commodities tracked by the Bureau of Labor Statistics. Panel B shows divergent price change for all CPI commodities. Divergent price change means that the choice of base year has a strong effect on the measurement of real GDP growth, as shown in Panel C. For sources and methods, see the Appendix. 
certainty. The problem in economics is twofold. First, we cannot reduce the uncertainty associated with the base-year problem. This is because the problem resides in the unit itself (prices). So long as price change is divergent, we cannot avoid the base-year problem.

Second, the economics discipline is not open about measurement uncertainty in real GDP. US government economists are aware of the base-year problem. ${ }^{3}$ But instead of admitting that this leads to uncertainty, they have taken the opposite road. The US government has imposed an official way of hiding the problem. This is called the 'chain-weighting' method (Steindel, 1995). It involves using a moving average over multiple base years. But this approach does not solve the underlying problem - indeed the problem cannot be solved. Prices are an unstable unit of measure, and no amount of mathematical wizardry can change this.

\subsection{The Quality-Change Problem}

The base-year problem is not the only issue with aggregating using 'real' monetary value. We must also measure the changing quality of commodities. Economists adopt the following convention: changes in commodity quality are converted into a change in economic quantity. This leads to a simple question: in what dimension do we measure quality change?

Consider the example of computers. Imagine an economy that in 1983, produced 100 Apple IIe computers. In 2017, the same economy produced 100 iMac Pros. Has economic output remained the same? If not, how much has it changed? To answer this question we must convert computer quality changes into quantity changes. But how should we do this? Here the dimension problem rears its head again. The quality-to-quantity conversion depends on the dimension of analysis. In terms of mass, computer output has probably declined in our hypothetical economy. But in terms of processing power, computer output has greatly increased. Thus, the choice of quality-change dimension affects our measure of output change.

Again, this is just the dimension problem. How we choose to measure output determines how we measure quality change (and vice versa). The choice then affects our results. But in economics we run into a further problem. Eco-

\footnotetext{
${ }^{3}$ For instance, US Federal Reserve economist Karl Whelan nicely captures real GDP uncertainty: "Take 1998 as an example: The growth rate of fixed-weight real GDP in this year was 4.5 percent if we use 1995 as the base year; using 1990 prices it was 6.5 percent; using 1980 prices it was 18.8 percent; and using 1970 prices, it was a stunning 37.4 percent!" (Whelan, 2002).
} 
nomic output is ostensibly measured using monetary value. But monetary value is unreliable for measuring quality change. Why? Because prices change over time even when commodities stay the same. Price change might reflect a change in a commodity's quality. But it might also reflect pure inflation. The logical conclusion should be that prices cannot measure quality change.

But this is not the conclusion reached by most price-index economists. Instead, they assume that prices reveal a hidden dimension that itself measures quality change. What is this dimension? It is utility - the pleasure derived from a product. Describing this 'hedonic' approach, the US Bureau of Labor Statistics writes:

In price index methodology, hedonic quality adjustment has come to mean the practice of decomposing an item into its constituent characteristics, obtaining estimates of the value of the utility derived from each characteristic, and using those value estimates to adjust prices when the quality of a good changes. (BLS, 2010) [emphasis added]

Let's unpack what is going on here. Price-index statisticians are using neoclassical theory to justify a particular way of measuring quality change. The idea is that utility is the relevant dimension of quality change. The problem is that utility is unobservable on its own (Nitzan and Bichler, 2009). Instead, it is 'revealed' through prices (Samuelson, 1938, 1948). This inversion makes the whole process circular. ${ }^{4}$ Indeed, Joan Robinson (1962) famously observed that utility is a circular concept: "Utility is the quality in commodities that makes individuals want to buy them, and the fact that individuals want to buy commodities shows that they have utility" [emphasis in original].

This discussion boils down to basic questions about the dimension of economic output. Is it (unobservable) utility, as hedonic quality adjustment implies? Or is it something else entirely? Economists need to take this dimension problem seriously.

The scale of the problem is illustrated in Figure 4. Here I return to the example of computers. Figure 4A plots measures of computer quality change adopted by 8 different OECD nations. Bars show the annual average percentage change in computer quality from 1995 to 2001. (For methods used to derive this data, see the Appendix). The dispersion in these measures has little to do with the computers themselves. (Computers are produced using a global supply chain. As a rough approximation, we can treat computers as being the same in all coun-

\footnotetext{
${ }^{4}$ Aside from circularity, there is another problem with this approach. Experiments indicate that individuals systematically violate the axioms of revealed preference theory (Sippel, 1997). In other words, the theory behind hedonic quality adjustment has been falsified.
} 
A. Measures of Computer Quality Change

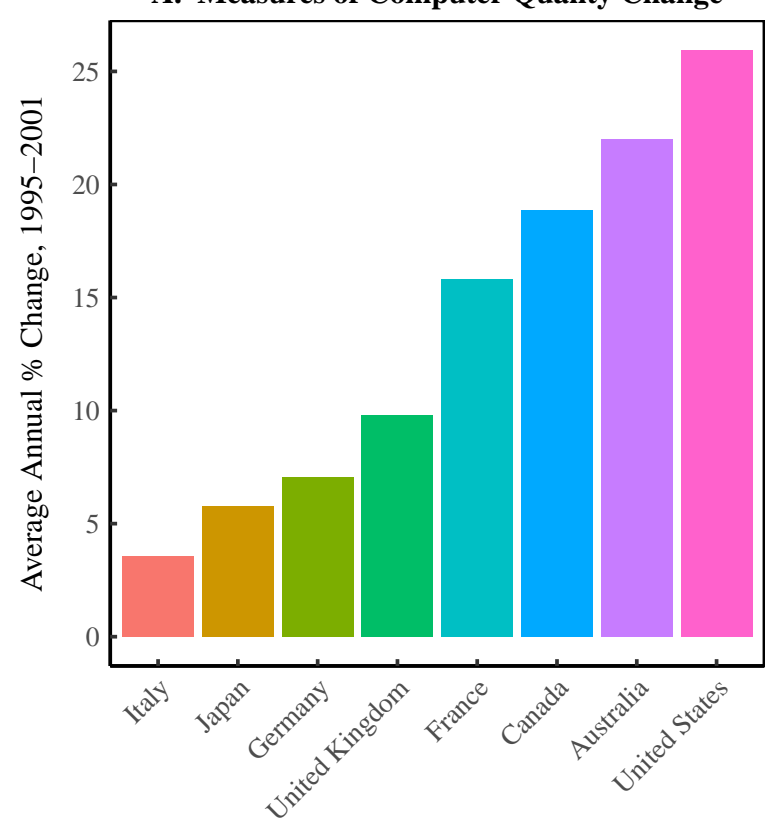

B. Hypothetical Computer Output Growth

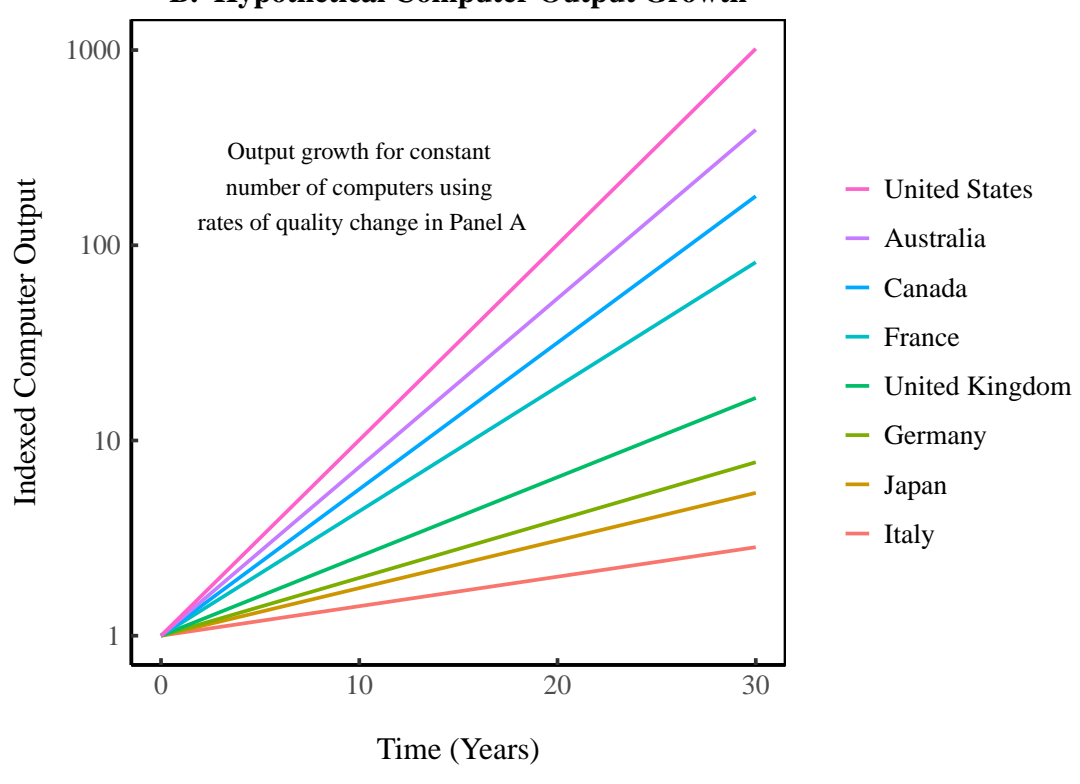

Figure 4: Divergent Measures of Computer Quality Change

This figure illustrates the dispersion in national estimates for rate of change of computer quality. Panel A shows computer quality change estimates for 8 OECD nations. Bars represent the average annual growth rate of computer quality between 1995 to 2001. Panel B shows how these quality change measurements would affect the growth of computer 'output' over 30 years. Assuming the number of computers produced remains the same in each year, the different quality adjustments lead to divergent measures of computer output growth spanning 3 orders of magnitude.

tries). Instead, this dispersion results from the different methods used to measure computer quality change. Summarizing the methods in 2004, the OECD observes:

The United States, Canada, France and Australia employ hedonic methods, and show the fastest rates of price decline. Although a hedonic price index has recently been developed in Germany, and introduced into the consumer price index, the investment deflator shown here is still based on the previous methodology. This explains its slower rate of change. No hedonic adjustment is carried out in Italy and in the United Kingdom. Japan constructs a hedonic producer price index for ICT hardware but it is not clear whether this deflator is also used in the national accounts. (OECD, 2004)

The scale of this quality-change dispersion is deceptively large. Consider what happens when we project it over thirty years. We assume that the number 
of computers produced in each country remains constant over time. But we continue to apply the quality-change adjustments shown in Figure 4A. How is computer output affected?

Remember that quality change metrics convert qualities into quantities. If the quality of computers improves by a factor of 2 , this gets converted into a factor of 2 growth in computer quantity. Figure 4 shows the results of a thirty-year extrapolation. The differing quality-change adjustments lead to a 3 orders of magnitude disparity in the measured growth of computer output.

This uncertainty demonstrates a fundamental aspect of the aggregation problem. There is no 'correct' way to convert qualities into quantities. Any such conversion depends on our goals, which will determine the dimension we consider appropriate. And different approaches can lead to wildly different measures. This epistemological predicament is not dealt with honestly by economists.

Again and again, subjective dimensional decisions are not recognized as such. Economists assume that utility is the 'correct' dimension of quality change. They turn to utility because prices themselves are an unreliable measure of quality change. And yet utility is never actually observed. It is 'inferred' from prices - the very unit that proved unreliable in the first place. This whole process serves to mask a myriad of subjective decisions about how quality change is measured. ${ }^{5}$ The result is significant hidden uncertainty in the measure of 'real' monetary value.

\subsection{The Failure of 'Real' Monetary Value: Some Implications}

My goal in this section has been to show what goes wrong when we use monetary value as the aggregation dimension. Here is a summary:

1. Prices are an unstable unit;

2. 'Correcting' for this instability requires subjective decisions;

3. This causes significant uncertainty in measures of 'real' monetary value.

4. Governments do not report this uncertainty.

These problems have important implications for ecological and biophysical economists. I explore some of these below.

\footnotetext{
${ }^{5}$ For a thorough review of the many subjective choices used in quality-change adjustments, see Nitzan (1992).
} 


\section{Implications for Boundary Reforms of the National Accounts}

For those who seek national accounts boundary reforms, the above problems should cause some soul searching. Even when we accept the boundary choices made by the national accounts, the system still fails. A major goal of the national accounts is to objectively measure the growth of economic production. Yet the system cannot deliver this goal. The need to 'correct' for inflation causes unavoidable ambiguity in real GDP and other 'quantity' measures (such as the capital stock).

Given this ambiguity, is it worth reforming the national accounts to include environmental and social externalities? I argue that it is not. When we do so, we simply increase the level of ambiguity in our measure. Not only do we keep the ambiguity in 'correcting' for inflation, we add the even greater ambiguity of valuing non-market items. Moreover, ecological economists often use neoclassical methods for valuing non-market items. At the very least, we need to be aware of the problems with these methods, and investigate how alternative methods would change our results. (For a critical discussion of neoclassical valuation, see Diamond and Hausman 1994; Dore 1996; Eberle and Hayden 1991). When it comes to sustainability issues, I argue that the national accounts are not worth reforming. The problems with using monetary value as the dimension of analysis are simply too severe.

\section{Implications for Economic Growth Accounting}

Let's move on and consider how 'real' monetary value ambiguity impacts the field of 'growth accounting'. This field seeks to quantify how different factors (such as labor and capital) drive economic growth. Mainstream growth accounting has tended to ignored the role of energy (and other natural resources). Ecological and biophysical economists have devoted significant effort to fixing this neglect. Over the last 40 years, many studies have analyzed energy's role in driving the growth of real GDP (Ayres and Warr, 2005, 2010; Beaudreau, 1998; Cleveland et al, 1984; Hall et al, 2001; Hannon and Joyce, 1981; Kummel, 1982, 1989; Kummel et al, 1985, 2000; Kaufmann, 1992).

But aside from neglecting natural resources, there is a more basic flaw with growth accounting. The field assumes that real GDP is an unambiguous measure of economic output. But is it? As Figure 3C shows, there is significant ambiguity in the growth or real GDP. This is because the calculation of real GDP requires enumerable subjective decisions. Given this subjectivity, I argue that the growth of real GDP is not worth explaining. 
Consider the following thought experiment. Using the tools of growth accounting, we find that the growth of energy use accounts for $70 \%$ of the growth of US real GDP. Suppose that the government then adopts different methodological decisions. These lead to a large revision in GDP growth (as Fig. 3B shows is possible). We find that energy growth now accounts for a very different fraction of real GDP growth. This raises an uncomfortable question. Can the government's subjective decisions change the role that energy plays in the economy? One hopes not. Instead, the logical conclusion is that we are trying to explain something that is not worth explaining.

But if we abandon real GDP, what should economic growth theory seek to explain? One possibility is to focus on the growth of biophysical flows. The importance of these flows follows directly from thermodynamic principles (GeorgescuRoegen, 1971; Kondepudi and Prigogine, 1998; Hall and Klitgaard, 2012; Prigogine et al, 1984). Importantly, they can be measured in well-defined biophysical dimensions. Fix (2015) presents a first attempt at this type of approach (focusing on energy). Of course, focusing on biophysical flows does not make the aggregation problem go away (Giampietro et al, 2013). But at the very least, it ensures a stable unit of analysis - something that cannot be said for monetary value.

\subsection{Summary: A New Old Problem}

Although the problems with aggregating 'real' monetary value are severe, they are not new. Most were highlighted more than sixty years ago in the 'Cambridge capital controversy'. ${ }^{6}$ This was a debate in the 1950s and 1960s between economists in Cambridge, England and Cambridge, Massachusetts. Joan Robinson (1953) began the debate when she asked — in what unit is capital measured? This prompted a protracted exchange that culminating in the Cambridge, England school demonstrating that there is no way to measure the quantity of capital independently of prices and distribution (Hodgson, 2005).

Unfortunately, the conclusions of the Cambridge capital controversy have been mostly ignored by mainstream economists. Why? The conclusions are likely too discomforting. The national accounts cannot unambiguously measure the growth of the capital stock or economic output. If we accept this critique, it leaves a gaping hole in the heart of economic theory.

\footnotetext{
${ }^{6}$ For a summary of the Cambridge debate, see Cohen and Harcourt (2003), Felipe and Fisher (2003), Harcourt (2015). For a broad discussion of the problems with measuring capital, see Nitzan and Bichler (2009).
} 


\section{Aggregation and 'Optimal' Decision Making}

The implications of the aggregation dimension problem are too extensive to explore fully here. But I do want to highlight how this problem affects the search for 'optimal' policy. Optimization plays a major role in sustainability policy discussions. But is it a sound approach? When we view policy optimization through a dimensional lens, some gaping flaws become evident.

\subsection{The Search for Social Optimums}

Neoclassical economics claims it can identify optimal policy that is 'best' for everybody. This claim is so important that it has been cited as a core goal of economics:

Making optimal use of scarce resources, that is, maximizing subject to constraints, is the central theme of economics" (Dixit, 1990) [emphasis added].

Thus, economists have theories for (among other things) optimal taxation (Sandmo, 1976), optimal investment (Abel, 1983), optimal government size (Karras, 1996), optimal economic growth (Koopmans, 1965), optimal levels of pollution control (Kwerel, 1977), optimal abatement of CO2 emissions (Nordhaus, 1992; Goulder and Mathai, 2000), optimal use of resources (Burt, 1964; Forster, 1980), and optimal population size (Eckstein and Wolpin, 1985).

These theories may seem arcane, but they have a real impact on government policy. In his work on optimal climate-change policy, William Nordhaus claimed that a "modest carbon tax" was preferable to "rigid emissions stabilization" (Nordhaus, 1992). Politicians have used this work to justify the tepid climate policy seen to date (Linden, 2018).

\subsection{Dimensional Choices Affect the Optimum}

The problem with using optimization for decision-making is that it requires unidimensional aggregation. Only functions that return a single dimension can be optimized. Functions that return two or more dimensions do not have optimums - they have trade offs. Thus to seek optimal policy, one must decide on a single dimension of analysis. Optimization therefore inherits all of the issues associated with aggregation itself. When we seek 'optimal' policy, dimensional choices will affect the aggregation and thus the optimum.

To illustrate how dimensional choices affect optimization, I return to the example of a stock of apples and bread slices. Suppose we need to maximize 

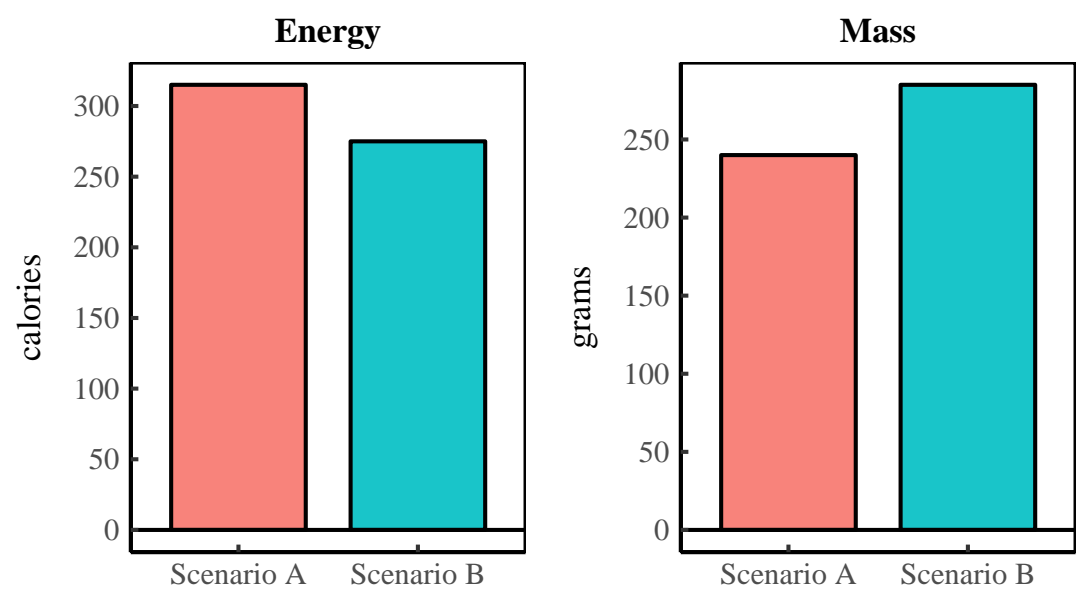

Scenario A:
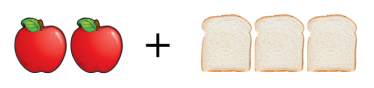

Scenario B:

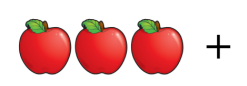

Figure 5: Measurements of the Maximum Stock of Apples and Bread Slices

Which scenario (A or B) maximizes the apple-bread stock? This figure shows how the choice of dimension affects the maximizing scenario. When measured in terms of caloric energy (left), Scenario A maximizes the stock. However, when measured in terms of mass, Scenario B maximizes the stock. Calculations use values from Table 1.

our stock by choosing between two scenarios. In Scenario A, we have 3 apples and 2 bread slices, while in Scenario B, we have 2 apples and 3 bread slices (see Fig. 5). Which stock is larger?

The problem is that without defining a single dimension to be maximized, this question has no meaning. Scenario A and Scenario B involve an incommensurable trade-off between an additional apple or an additional bread slice. To make a judgment about the maximum stock, we must make the scenarios commensurable. This requires choosing a single dimension of analysis. The problem is that the choice of aggregation dimension affects what we find. As shown in Figure 5, when we aggregate in terms of energy, we find that Scenario A maximizes the apple-bread stock. However, when we aggregate in terms of mass, Scenario B maximizes the stock. This is because dimensional choice affects the relative weighting between apples and bread slices.

As this example illustrates, optimization is affected by subjective dimensional decisions. Different decisions will lead to different 'optimal' solutions. The search for 'optimal' policy thus depends crucially on our goals and our resulting choice of dimensions. 


\subsection{An Aggregation and Optimization Checklist}

Because optimization depends on pre-analytic decisions, it must be used carefully. Optimization is a powerful decision-making tool when used appropriately. Unfortunately, it is also a powerful tool for persuasion that can be easily misused. To guard against misuse, I suggest we ask the following questions of any optimization procedure:

1. Are the underlying goals well defined and uncontested?

2. Does the dimension of analysis follow unambiguously from the goals?

3. Does the dimension provide an objective way to weight attributes?

If we answer 'yes' to all three questions, then the optimization is likely unproblematic. But if we answer 'no' to one or more questions, then the use of optimization is likely pernicious. Let's consider some examples.

\section{Unproblematic Optimization}

Suppose we want to design a gasoline engine with fixed horsepower that uses as little fuel as possible. In this case the goal is clear - minimize fuel use for a given level of power output. From this goal, the relevant optimization dimension (gasoline energy input) follows unambiguously. The science of energetics then defines how to measure the energy content in fuel, ensuring that the weighting of attributes is determined objectively. In this situation, optimization is unproblematic.

\section{Vague and Contested Goals}

Let's move from this engineering example to the kind of problem that modern policy makers face. Suppose we need to craft climate change policy. What is our goal? Is it to lower greenhouse gas emissions? Or simply lower their growth? Is it to save human lives (now and in the future)? Is it to achieve sustainable economic growth? Is it to maximize the present value of human welfare? In sustainability situations such as this, our goals are rarely well defined. If we cannot agree on goals, then there is no point in searching for an 'optimal' solution, since this does not exist without first agreeing on goals.

\section{Ambiguous Dimensions}

Often policy makers simply define the goal to be achieved. (This is, after all, what politicians do). So let's consider a specific sustainability goal. Suppose we 
want to choose the automobile engine (diesel vs. gasoline) that will have the least 'environmental impact'.

The problem is that this goal does not lead unambiguously to a dimension of analysis. These leads to ambiguity in the 'best' choice of automobile. Consider two different interpretations of our goal. If 'environmental impact' means carbon emissions, then diesel is the superior technology. Diesel engines are more fuel efficient, and therefore emit less carbon dioxide. However, if 'environmental impact' means human health problems caused by particulate matter or nitrogen oxides, then diesel engines are worse than gasoline engines (Ghose, 2015).

Unfortunately this example is not a thought experiment. It has recently played out in Europe. To meet Kyoto obligations, many European countries promoted a rapid switch from gasoline to diesel cars. But policy makers did not consider how this would affect air quality. The widespread adoption of diesel engines led to a predictable rise in particulate matter pollution (Forrest, 2017). As a British civil servant put it, the policy choice meant deciding between "killing people today rather than saving lives tomorrow" (Vidal, 2015).

\section{Subjective Weighting of Attributes}

Let's continue with the gasoline vs. diesel engine question. But now we will think like economists. We assume that the relevant optimization dimension is monetary value. In other words, we will conduct a cost-benefit analysis.

The problem is that monetary value does not objectively weight different environmental impacts. First, there is the problem that inflation makes prices an unstable unit of analysis. Second, many (if not most) environmental impacts do not have a market price. Further subjective decisions are required to estimate this price.

Consider the impact of different types of emissions. Particulate pollution causes immediate, local deaths. However, carbon emissions will cause future, global deaths from climate change. How should we weight these different outcomes? First, there is the issue of pricing life, which is inherently subjective. Unsurprisingly, different approaches yield drastically different results. Historical valuation data presented in Viscusi and Aldy (2003) has a relative standard deviation of $138 \%$. To put this in context, the dispersion in human life valuation is about 35 times the dispersion of adult male height.

Then there is the issue of weighting future costs against those in the present. The practice in economics is to 'discount' the future. But the choice of discount rate is subjective and can lead to wildly different valuations. The most famous 
discounting controversy is likely the debate between Nicholas Stern and William Nordhaus. This was an argument about the 'correct' discount rate for climate change costs. The Stern Review (2006) found that drastic action was required to avert catastrophic future costs. However, Nordhaus (2007) found that action was far less urgent. What was the main difference? The Stern Review used a discount rate of $1.4 \%$, while Nordhaus used a discount rate of $6 \%$. Nitzan and Bichler (2009) point out the effect this has on future costs: "One thousand dollars' worth of environmental damage a hundred years from now, when discounted at 1.4 per cent, has a present value of $-\$ 249$ (negative since we measure cost). ... But the same one thousand dollars' worth of damage, discounted at 6 per cent, has a present value of only $-\$ 3$."

Economists continue to debate the 'correct' valuation method and the 'correct' discount rate. But this misses the point. The problem resides in the dimension itself. Monetary value does not provide an objective way to weight different outcomes. Instead, the analyst must make a host of subjective valuation decisions. These decisions then affect the 'optimal' policy. As a result, the 'optimal' policy does little more than reflect the preferences of the analyst.

\section{Optimization as a Political Tool}

The more we answer 'no' to the optimization checklist, the less appropriate it is to seek 'optimal' policy. If we answer 'no' to all three aggregation questions, then optimization is likely pernicious. Why? It hides subjective trade offs that are otherwise clearly visible. When used this way, optimization serves as a political tool. It takes a political debate over subjective trade offs and turns it into a technical dispute for 'experts'. This gives political and ethical preferences the appearance of scientific rigor.

\section{Addressing the Aggregation Problem}

The crux of the aggregation problem is the subjectivity of comparing the incommensurable. To aggregate, we must make subjective decisions about the dimension of analysis. These decisions then affect our results. There are no 'solutions' to the aggregation problem, if by 'solution' we mean a way to aggregate that involves no subjective decisions. But there are ways of addressing the problem. I outline three possibilities below. 


\subsection{Avoid Aggregation}

One response to the aggregation problem is to simply avoid aggregation. This is appropriate for sustainability issues where the relevant dimension is ambiguous and/or contested. If we cannot agree on the appropriate dimension, this is a sign that we should not be aggregating. Instead, we should leave incommensurable trade offs in their own 'natural' dimensions. For instance, we might measure habitat loss in dimensions of area, pollution in dimensions of mass, lives lost in dimensions of individuals, and so on. Ackerman (2008) recommends this route as an alternative to cost-benefit analysis:

Most of the information collected for a cost-benefit analysis is useful under any approach to deliberation. The problems arise only in the final steps of crunching everything into a single bottom-line number: monetizing non-monetary benefits, discounting future outcomes, and guesstimating the values of important uncertainties all have the effect of distorting and concealing the underlying data.

The advantage of not aggregating is that subjective trade offs remain clearly visible. This allows stakeholders to weight trade offs as they see fit, based on their own preferences.

\subsection{Use Biophysical Dimensions}

If we decide to aggregate, then we must use a dimension with well-defined units. This truism should hardly need stating. Objective measurement requires a precisely defined unit. And yet the majority of economists seem to ignore this fact. They continue to use prices to measure quantities such as economic output and the capital stock. But prices are a spectacularly unstable unit. This causes tremendous ambiguity in indexes of quantity derived from the national accounts.

If we value accurate measurement, then we need to stop measuring economic quantities using real monetary value. The obvious alternative is to use biophysical dimensions to measure economic scale. This will remove the problem of poorly defined units. But it means rethinking what we mean by 'economic growth' and 'capital accumulation'. It means we cannot speak of these quantities without first stipulating a dimension. And we should be prepared to find different results when we look at different dimensions. 


\subsection{Be Open About Subjectivity}

If we decide to aggregate, then we should be honest about the accompanying subjectivity. This requires being explicit about goals, and reporting dimensional decisions honestly and openly. This allows others to evaluate the reasoning behind the aggregation. It is the reasoning itself that gives the analysis meaning. Acknowledging this fact, Jonathan Nitzan writes:

... any scientific method of measuring ... must, to some extent, be anchored in our initial values. Indeed, it is these initial values which make our analysis worthy in the first place, so they must be clearly identified for that analysis to carry any weight. (Nitzan, 1992) [emphasis added]

When our assumptions are presented openly, they can be debated and tested. Ecological and biophysical economists should avoid the path taken by mainstream economics. If we hide our subjective aggregation decisions, or deny that they exist, we embrace the road to pseudoscience.

\section{Conclusions}

When the aggregation dimension problem is stated clearly, it borders on trivial. Aggregation requires comparing incommensurable items using a single dimension. How we choose to do this affects the resulting aggregation. This epistemological predicament is simple when identified. And yet it is easily forgotten. Why?

I think the root of the problem is that it is surprisingly easy to become oblivious to our own assumptions. As Richard Feynman (1974) said of science, "The first principle is that you must not fool yourself - and you are the easiest person to fool". The problem is that 'getting fooled' is a social process as much as an individual one. Karl Popper (1959) argued that many methodological choices in science are a result of convention. Founding thinkers make subjective decisions that are then adopted as conventions by the rest of the field. As conventions are institutionalized, they begin to appear like 'objective' procedures (Nitzan, 1992). Over time, we forget the subjective elements of our methods. When this happens, we collectively 'fool ourselves'.

With regard to aggregation, I have argued that mainstream economists have fooled themselves. They have decided to aggregate economic quantities using the dimension of monetary value. But prices, it turns out, are an unstable unit. As a result, many subjective decisions are required to adjust for price instability. Yet economists have convinced themselves that their methods are objective. As 
a result, the ambiguity in the national accounts remains hidden from the general observer.

If ecological and biophysical economists want a true 'science of sustainability', then we need to question the aggregation conventions of mainstream economics. For ecological economists, this has meant questioning the boundary decisions made by the national accounts. But there is a more basic question that we need to ask. Given the many flaws, do we want to keep aggregating economic quantities using 'real' monetary value? If not, what dimensions should we use to measure economic output? For that matter, what dimensions should we use to measure sustainability? These questions have no easy answers. But the most important step is recognizing that these dimension questions need to be asked.

\section{Supplementary Material}

Supplementary material for this paper is available at the Open Science Framework: https://osf.io/3smra/

\section{Conflicts of Interest}

The author states that there is no conflict of interest. 


\section{A Sources and Methods}

\section{Fig. 3}

Consumer price index data comes from the Bureau of Labor Statistics database, available at https://download.bls.gov/pub/time.series/cu/. Commodities that exist in 1935 are indexed to 1 in that year. However, many commodities are introduced after 1935. I deal with these new commodities by indexing them to the average indexed price of the existing commodities in the sample.

Real GDP data comes from the Federal Reserve Bank of Philadelphia, series routputmvqd. This dataset contains 'vintage' real GDP calculations using different base years between 1965 and 2017. The source data does not calculate real GDP for years later than the corresponding base year. For instance, GDP data for base year 1995 ends in 1995. For comparison, I project real GDP growth up to 2017 (for all series). I do this by first calculating the difference in average growth rates between the given base-year series $\left(g_{\text {base }}\right)$ and the 2017 series $\left(\bar{g}_{2017}\right)$ :

$$
\bar{g}_{\Delta}=\left.\left(\bar{g}_{2017}-\bar{g}_{\text {base }}\right)\right|_{1947} ^{\text {base }}
$$

Here $\bar{g}$ indicates the geometric mean. The average is calculated from 1947 to the base year in question. I then use the average growth rate difference $\bar{g}_{\Delta}$ to project the base-year series up to 2017:

$$
g_{\text {project }}=\left.\left(g_{2017}-\bar{g}_{\Delta}\right)\right|_{\text {base }} ^{2017}
$$

US population data comes from the U.S. Bureau of the Census, retrieved from FRED https://fred.stlouisfed.org/series/POP. Population data prior to 1952 comes from the Historical Statistics of the United States series Aa6.

\section{Fig. 4}

Computer quality-change adjustments are estimated as follows. We begin with the definition of price index change - the change in price less the change in quality:

$$
\Delta \text { price index }=\Delta \text { price }-\Delta \text { quality }
$$


This implies that computer quality change is given by:

$$
\Delta \text { quality }_{\text {computer }}=\Delta \text { price }_{\text {computer }}-\Delta \text { price index }_{\text {computer }}
$$

OECD (2004) provides the change in computer price index between 19952001 for 8 OECD nations. To get the change in computer quality, we need computer price-change estimates for each country. However, this data is difficult to obtain. As an approximation, I assume that the change in computer price can be proxied by the official inflation rate in each country. This gives the following method for estimating the rate of computer quality change:

$$
\Delta \text { quality }_{\text {computer }} \approx \Delta \text { inflation }-\Delta \text { price index } \text { computer }
$$

For this estimate, I use GDP deflator data from the World Bank (series NY.GDP.DEFL.KD.ZG). Since official inflation rates in our 8 OECD nations are very similar, virtually all of the dispersion in computer quality change comes from dispersion in the computer price index. 


\section{References}

Abel AB (1983) Optimal investment under uncertainty. The American Economic Review 73(1):228-233

Ackerman F (2008) Critique of cost-benefit analysis, and alternative approaches to decision-making. Tech. rep., London

Ayres R, Warr B (2005) Accounting for growth: the role of physical work. Structural Change and Economic Dynamics 16(2):181-209

Ayres RU, Warr B (2010) The economic growth engine: how energy and work drive material prosperity. Edward Elgar Publishing, Cheltenham, UK

Beaudreau BC (1998) Energy and Organization: Growth and Distribution Reexamined. Greenwood Publishing Group, Westwood, CT

Blas J, Wallis W (2014) Nigeria almost doubles GDP in recalculation. Financial Times

BLS (2010) Frequently Asked Questions about Hedonic Quality Adjustment in the CPI: U.S. Bureau of Labor Statistics

Burt OR (1964) Optimal resource use over time with an application to ground water. Management science 11(1):80-93

Cleveland C, Costanza R, Hall C, Kaufmann R (1984) Energy and the US economy: a biophysical perspective. Science 225(4665):890-897

Cohen AJ, Harcourt GC (2003) Retrospectives: Whatever happened to the Cambridge capital theory controversies? Journal of Economic Perspectives 17(1):199-214

Colacchio G (2018) Marginal Product of Labor. URL https://www. encyclopedia.com/social-sciences/applied-and-social-sciences-magazines/ labor-marginal-product

Costanza R, Daly HE (1992) Natural capital and sustainable development. Conservation biology 6(1):37-46

Daly H, Farley J (2011) Ecological Economics : Principles and Applications. Island Press, Washington

Daly HE, Cobb JB (1994) For the common good: Redirecting the economy toward community, the environment, and a sustainable future. Beacon Press 
Diamond PA, Hausman JA (1994) Contingent valuation: is some number better than no number? Journal of economic perspectives 8(4):45-64

Dilke OAW, Dilke OAW (1987) Mathematics and measurement, vol 2. Univ of California Press

Dixit AK (1990) Optimization in economic theory. Oxford University Press, New York

Dixon JA, Hamilton K (1996) Expanding the measure of wealth. Finance and Development 33(4):15

Dodds S (1997) Towards a 'science of sustainability': improving the way ecological economics understands human well-being. Ecological economics 23(2):95-111

Dore $\mathrm{MH}$ (1996) The problem of valuation in neoclassical environmental economics. Environmental Ethics 18(1):65-70

Eberle WD, Hayden FG (1991) Critique of contingent valuation and travel cost methods for valuing natural resources and ecosystems. Journal of Economic Issues 25(3):649-687

Eckstein Z, Wolpin KI (1985) Endogenous fertility and optimal population size. Journal of Public Economics 27(1):93-106

Edgeworth FY (1887) Measurement of Change in Value of Money I. First Memorandum presented to the British Association for the Advancement of Science Reprinted in his Papers Relating to Political Economy 1:198-259

Felipe J, Fisher FM (2003) Aggregation in production functions: what applied economists should know. Metroeconomica 54(2-3):208-262

Feynman RP (1974) Cargo cult science. Engineering and Science 37(7):10-13

Fix B (2015) Rethinking Economic Growth Theory from a Biophysical Perspective. Springer, New York

Forrest A (2017) The death of diesel: has the one-time wonder fuel become the new asbestos? The Guardian

Forster BA (1980) Optimal energy use in a polluted environment. Journal of Environmental Economics and Management 7(4):321-333, DOI 10.1016/ 0095-0696(80)90025-X 
Georgescu-Roegen N (1971) The entropy law and the economic process. Harvard University Press, Cambridge, MA

Ghose T (2015) Volkswagen Scandal: Why Is It So Hard to Make Clean Diesel Cars?

Giampietro M, Allen TFH, Mayumi K (2006) The epistemological predicament associated with purposive quantitative analysis. Ecological Complexity $3(4): 307-327$

Giampietro M, Mayumi K, Sorman A (2013) Energy Analysis for a Sustainable Future: Multi-Scale Integrated Analysis of Societal and Ecosystem Metabolism. Routledge, New York

Goulder LH, Mathai K (2000) Optimal CO2 abatement in the presence of induced technological change. Journal of Environmental Economics and management $39(1): 1-38$

Hall C, Klitgaard K (2012) Energy and the Wealth of Nations: Understanding the Biophysical Economy. Springer, New York

Hall C, Lindenberger D, Kummel R, Kroeger T, Eichhorn W (2001) The Need to Reintegrate the Natural Sciences with Economics. BioScience 51(8):663-673

Hannon B, Joyce J (1981) Energy and technical progress. Energy 6(2):187-195

Harcourt GC (2015) On the Cambridge, England, Critique of the Marginal Productivity Theory of Distribution. Review of Radical Political Economics 47(2):243-255, DOI 10.1177/0486613414557915

Hodgson GM (2005) The fate of the Cambridge capital controversy. In: Capital controversy, post Keynesian economics and the history of economic thought, Routledge, pp 112-125

Jerven M (2012) Lies, damn lies and GDP. The Guardian

Jerven M (2014) Economic Growth and Measurement Reconsidered in Botswana, Kenya, Tanzania, and Zambia, 1965-1995. Oxford University Press, Oxford

Karras G (1996) The optimal government size: further international evidence on the productivity of government services. Economic inquiry 34(2):193-203 
Kaufmann RK (1992) A biophysical analysis of the energy/real GDP ratio: implications for substitution and technical change. Ecological Economics 6(1):3556

Keen S (2001) Debunking Economics: The Naked Emperor of the Social Sciences. Zed Books, New York

Kondepudi D, Prigogine I (1998) Modern Thermodynamics: from Heat Engines to Dissipative Structures. John Wiley \& Sons, Chichester

Koopmans TC (1965) On the concept of optimal economic growth. Cowles Foundation Discussion Papers 163

Kubiszewski I, Costanza R, Franco C, Lawn P, Talberth J, Jackson T, Aylmer C (2013) Beyond GDP: Measuring and achieving global genuine progress. Ecological Economics 93:57-68

Kummel R (1982) The impact of energy on industrial growth. Energy 7(2):189203

Kummel R (1989) Energy as a factor of production and entropy as a pollution indicator in macroeconomic modelling. Ecological Economics 1(2):161-180

Kummel R, Strassl W, Gossner A, Eichhorn W (1985) Technical progress and energy dependent production functions. Journal of Economics 45(3):285-311

Kummel R, Lindenberger D, Eichhorn W (2000) The productive power of energy and economic evolution. Indian Journal of Applied Economics 8(2):1-26

Kwerel E (1977) To tell the truth: Imperfect information and optimal pollution control. The Review of Economic Studies pp 595-601

Linden E (2018) The economics Nobel went to a guy who enabled climate change denial and delay. URL http://www.latimes.com/opinion/op-ed/ la-oe-linden-nobel-economics-mistake-20181025-story.html

Messac L (2018) Outside the Economy: Women's Work and Feminist Economics in the Construction and Critique of National Income Accounting. The Journal of Imperial and Commonwealth History 46(3):552-578, DOI 10.1080/03086534.2018.1431436

Mill JS (1848) Principles of Political Economy. George Routledge and Sons, Manchester 
Mirowski P (1991) More Heat Than Light: Economics as Social Physics, Physics as Nature's Economics. Cambridge Univ Pr

Nitzan J (1992) Inflation as restructuring. A theoretical and empirical account of the US experience. PhD thesis, McGill University

Nitzan J, Bichler S (2009) Capital as Power: A Study of Order and Creorder. Routledge, New York

Nordhaus WD (1992) An optimal transition path for controlling greenhouse gases. Science 258(5086):1315-1319

Nordhaus WD (2007) A review of the Stern review on the economics of climate change. Journal of economic literature 45(3):686-702

OECD (2004) The Economic Impact of ICT. Measurement, Evidence and Implications. Tech. rep., Organisation for Economic Cooperation and Development, Paris

Petley BW (1983) New definition of the metre. Nature 303(5916):373-376

Popper K (1959) The Logic of Scientific Discovery. Hutchinson \& Co., New York

Prigogine I, Stengers I, Toffler A (1984) Order out of Chaos. Bantam, Toronto

Robinson J (1953) The production function and the theory of capital. The Review of Economic Studies 21(2):81-106

Robinson J (1962) Economic philosophy. Aldine Pub. Co., Chicago

Samuelson PA (1938) A note on the pure theory of consumer's behaviour. Economica 5(17):61-71

Samuelson PA (1948) Consumption theory in terms of revealed preference. Economica 15(60):243-253

Sandmo A (1976) Optimal taxation: An introduction to the literature. Journal of public economics 6(1-2):37-54

Sippel R (1997) An experiment on the pure theory of consumer's behaviour. The Economic Journal 107(444):1431-1444

Smith GD, Hart C, Upton M, Hole D, Gillis C, Watt G, Hawthorne V (2000) Height and risk of death among men and women: aetiological implications of associations with cardiorespiratory disease and cancer mortality. Journal of Epidemiology and Community Health 54(2):97-103 
Solow RM (1956) A contribution to the theory of economic growth. The Quarterly Journal of Economics 70(1):65-94

Steindel C (1995) Chain-weighting: The New Approach to Measuring GDP. Current Issues in Economics and Finance, Federal Reserve Bank of New York 1(9)

Stern N, Peters S, Bakhshi V, Bowen A, Cameron C, Catovsky S, Crane D, Cruickshank S, Dietz S, Edmonson N (2006) Stern Review: The economics of climate change, vol 30. HM treasury London

Vidal J (2015) The rise of diesel in Europe: the impact on health and pollution. The Guardian

Vining DR, Elwertowski TC (1976) The relationship between relative prices and the general price level. The American Economic Review 66(4):699-708

Viscusi WK, Aldy JE (2003) The value of a statistical life: a critical review of market estimates throughout the world. Journal of risk and uncertainty $27(1)$ :576

Waring M (1999) Counting for nothing: What men value and what women are worth. University of Toronto Press

Whelan K (2002) A guide to US chain aggregated NIPA data. Review of income and wealth 48(2):217-233 